Residual Stress Analysis in Thick Uranium Films

A. M. Hodge, R. J. Foreman, G. F. Gallegos

December 14, 2004

Journal of Nuclear Materials 
This document was prepared as an account of work sponsored by an agency of the United States Government. Neither the United States Government nor the University of California nor any of their employees, makes any warranty, express or implied, or assumes any legal liability or responsibility for the accuracy, completeness, or usefulness of any information, apparatus, product, or process disclosed, or represents that its use would not infringe privately owned rights. Reference herein to any specific commercial product, process, or service by trade name, trademark, manufacturer, or otherwise, does not necessarily constitute or imply its endorsement, recommendation, or favoring by the United States Government or the University of California. The views and opinions of authors expressed herein do not necessarily state or reflect those of the United States Government or the University of California, and shall not be used for advertising or product endorsement purposes. 


\title{
Residual Stress Analysis in Thick Uranium Films
}

\author{
A.M. Hodge ${ }^{1, \dagger}$, R.J. Foreman ${ }^{1}$, G.F. Gallegos ${ }^{2}$ \\ ${ }^{1}$ Materials Science and Technology Division, ${ }^{2}$ Manufacturing and Materials Engineering \\ Division, \\ Lawrence Livermore National Laboratory \\ 7000 East Avenue, Livermore, CA 94550
}

\begin{abstract}
Residual stress analysis was performed on thick, 1.0 to $25 \mu \mathrm{m}$, depleted Uranium (DU) films deposited on an Al substrate by magnetron sputtering. Two distinct characterization techniques were used to measure substrate curvature before and after deposition. Stress evaluation was performed using the Benabdi/Roche equation, which is based on beam theory of a bi-layer material. The residual stress evolution was studied as a function of coating thickness and applied negative bias voltage (0-300V). The stresses developed were always compressive; however, increasing the coating thickness and applying a bias voltage presented a trend towards more tensile stresses and thus an overall reduction of residual stresses.
\end{abstract}

${ }^{\dagger}$ Author to whom correspondence should be send 
To be submitted to Journal of Nuclear Materials - not for circulation

\section{Introduction}

Difficulties in conventional machining of Uranium due to work-hardening under the slightest tool pressure [1], and the almost instant oxide layer formation [2], present a challenge when high precision parts are needed. Coating complex parts with Uranium would present an alternative to machining. Currently, there are some studies on magnetron sputtered $U$ which have focused on the substrate/coating diffusion layers with a very thin layer $U$ layer $(<1 \mathrm{~nm})[3,4]$, and one study which focused on coating $U$ to prevent oxidation [5]; however, the study of residual stresses in Uranium films is an unexplored field.

Residual stress evolution in coatings has been an extensive area of research, mostly focusing on thin films (i.e. tc<<ts) [6, 7] with some exceptions [8]. Residual stresses in physical vapor deposition (PVD) films emerge from two factors: intrinsic stress during film growth and extrinsic stress due to thermal effects. For coatings deposited by PVD techniques, changing coating parameters such as gas pressure, temperature and applied negative bias voltage has been shown to change the stresses as well as the texture of the materials [9-11]. Currently, changes in PVD coating parameters and their effects on the coating structure are estimated by using the Thornton 4-zone diagram [8]; however, $\mathrm{U}$ is a complex material due to a highly anisotropic crystal structure, multiple phases, and a $5 \mathrm{f}$ electronic structure, and therefore it is not expected to behave as a typical metal film.

Techniques for measuring the deformation caused by the stresses developed during deposition fall into two categories: lattice based strain methods and surface 
To be submitted to Journal of Nuclear Materials - not for circulation

curvature based methods. Lattice based methods such as x-ray diffraction cannot be used for highly anisotropic materials such as Uranium; therefore, surface curvature methods such as profilometry should be used. Previous studies on other metals have shown good accuracy for surface curvature methods [12]. Only small residual stress value deviations were found in thin coatings when comparing values calculated from x-ray diffraction techniques vs. laser curvature and profilometry techniques [13].

In this paper we present the first study of residual stresses in various DU coatings focusing on thick DU coatings and including a study of the stress evolution as a function of applied negative bias voltage and film thickness. The overall surface deformation was measured using white light profilometry, stylus profilometry and applying the use of the Benabdi/Roche equation, which is based on beam theory of a bi-layer material.

\section{Experimental Procedures}

A UHV compatible magnetron sputtering source was used with $125 \mathrm{~W}$ power, a pressure of 10 mTorr and a negative bias voltage of 0 to $300 \mathrm{~V}$. The substrate used was a $200 \mu \mathrm{m}$ thick, lapped 25 mm diameter Al 1100 - H112 disk. Substrates were heat treated to relieve stress due to lapping at $300^{\circ} \mathrm{C}$ for 2 hours and tested by Vickers microhardness. The Al substrates were cleaned before placing them in the vacuum chamber; while in the chamber, the substrate was ion milled for 30 seconds and then coated with $\sim 30 \mathrm{~nm}$ of Ti for bonding purposes. Deposition times varied between 5 min and 4 hours, depending on the desired film thickness. There were three substrates per coating run and a total of seven runs; two of the runs were used exclusively to check deposition rates. The substrate temperature was monitored during the deposition runs. Two distinct apparatus, 
To be submitted to Journal of Nuclear Materials - not for circulation

a white light profilometer (Zygo NewView 5000, Middlefield, CT) and a stylus profilometer (Ambios XP, Santa Cruz, CA), were used to acquire the sample curvature profile before and after coating deposition. Scans were performed in four different directions, which were marked before coating; additionally, the markings were covered by a mask during the coating process in order to compare before and after profiles. The stylus profilometer and SEM were used to determine coating thickness and surface roughness. After deposition, density measurements were performed on the coated samples by Archimedes method in FC-43.

\section{Results and Discussion}

\subsection{Coating Characterization}

Extensive measures were made to characterize the samples the same day the coating was completed in order to minimize any effects due to oxidation. Density tests performed by Archimedes method show the DU coatings to be $99 \%$ dense when compared to the theoretical density of $U\left(19.4 \mathrm{~g} / \mathrm{cm}^{3}\right)$. Furthermore, all coatings appear to have a smooth interface to the substrate; EDS analysis confirmed that there were only U peaks at the substrate/coating boundary. There is no sign of an intermetallic layer by EDS analysis; however, a faint Ti signal can be detected at the highest magnifications. X-ray diffraction performed on the $U$ films show a highly textured sample with only $U$ peaks present.

Figure 1a depicts a SEM micrograph of a representative cross-section of the $U$ coating, which shows a homogeneous coating througthout the sample. Coating thickness was also measured with the stylus profilometer by scanning the step height between the 
To be submitted to Journal of Nuclear Materials - not for circulation

mask and unmasked region. The coating had a smooth, mirror-like surface and is made up of dense fiber-like grains, as can be seen in Figure 1b, which shows a typical unpolished fracture surface of the coating. This particular coating description was described by Thornton and Hoffman [14] and is considered to be in "region T", which is the transition region and is known to form large intrinsic stresses. Overall, the microstructure of the Uranium coatings seems to fit well when compared to the predicted microstructure based on argon pressure vs. T/Tm Thornton diagram (where $\mathrm{T}$ is the substrate temperature and $\mathrm{Tm}$ is the melting temperature of the coating); for this case, $\mathrm{P}=$ $10 \mathrm{mTorr}$ and $\mathrm{T} / \mathrm{Tm}=0.2$. To our knowledge, this is the first time that a complex element such as Uranium has been shown to fit the predicted structure. Use of the Thornton diagram would allow selective changes in the coating microstructure by changing the coating parameters.

Figure 2a shows $20 \mathrm{~mm}$ long scan lines A, B, C, and D taken by white light profilometry. Smaller scans $(2 \mathrm{~mm})$ were performed at the edge of the mask/unmasked region for a total of eight measurements for thickness for each sample. We found that the standard deviation on the thickness was less than one micron at any given scan for the 2025 microns thick coatings. Figure $2 \mathbf{b}$ shows a plot of the before- and after-coating profile for line $\mathrm{C}$, disc 5; for this particular disc line $\mathrm{C}$ had the highest deflection. Note that the diameter is in $\mathrm{mm}$ and the total deflection is in microns. The maximum deflection ( $\delta$ max) of scans A, B, C and D are averaged to show the average highest deflection for each disc. Similar plots were done for each scan line before and after coating; the before profile was subtracted from the after profile to give the total 
To be submitted to Journal of Nuclear Materials - not for circulation

deflection. The peak of the deflection is right at the center of the disk and it is labeled as Smax. Deflection measurements were performed by white light profilometry.

Table 1 presents a summary of the average of the maximum deflection $(\delta m a x)$ from line scans A, B, C, D at a given thickness. Note that the coating diameter was 20 mm for all samples so the $\delta$ max shows a real decrease as a function of substrate bias.

Table 1. Deflection and thickness measurements by profilometry

\begin{tabular}{|l|l|l|l|}
\hline Coating \# & Bias & Coating & Smax \\
& $(\mathrm{V})$ & $\begin{array}{r}\text { Thickness } \\
(\mu \mathrm{m})\end{array}$ & average $(\mu \mathrm{m})$ \\
\hline 3 & 0 & 24.8 & 700 \\
\hline 4 & 0 & 20 & 700 \\
\hline 5 & -200 & 20.6 & 435 \\
\hline 8 & -300 & 23.7 & 435 \\
\hline 9 & -300 & 26.4 & 383 \\
\hline
\end{tabular}

We have shown by the use of stylus profilometry to measure coating thickness and white light profilometry to measure deflection, that can we obtain a good measurement of the total disc deformation and the film thickness; these values provide the necessary parameters to calculate the residual stresses. Furthermore, SEM has been used to verify the thickness measurements. 
To be submitted to Journal of Nuclear Materials - not for circulation

\subsection{Residual Stress Equations}

Since our measurements are performed ex-situ, the residual stresses presented here are the total stresses due to intrinsic and extrinsic factors. In this particular work, we will make the assumption that there is no in-plane deformation of the coated surface, i.e the deflection is caused only by the free contraction or elongation of the coating layer [15]. This narrows the available equations to Stoney (eqn.1), Röll (eqn.2)and the Benabdi/Roche (BR) (eqn 3) equation [15-17]. The three equations mentioned also assumed a constant residual stress distribution over the whole coating; we believe that this is a fair assumption because our film/substrate thickness ratio is $\sim 13 \%$. Equations 1 3 have been further modified to include a bi-axial modulus as suggested by Timoshenko [18].

Most of the current literature addressing stress analysis focuses on thin films for which Stoney's equation is widely used; however, this equation has a valid thickness ratio $\left(\mathrm{t}_{\mathrm{c}} / \mathrm{t}_{\mathrm{s}}\right)$ limit of $\sim 5 \%$ of the coating thickness [6]. As can be seen in equation 1 , Stoney's equation takes into account the Elastic Modulus and Poisson ratio of the substrate only. However, as the film thickness approaches the substrate thickness, there are multiple parameters from the coating that must be taken into account in order to accurately calculate the residual stresses. The main difference between equations 1-3 is the addition of higher order terms and it is further discussed elsewhere [15].

For thick coatings, there are multiple factors which affect the stress behavior and are a combination of the coating substrate properties. For example, the ratio of the elastic modulus of the coating and the substrate $\left(\mathrm{E}_{\mathrm{c}} / \mathrm{E}_{\mathrm{s}}\right)$, which we will call $\alpha$. There are multiple configurations for $\alpha$ such as: compliant substrate/compliant coating $\alpha=1$, stiff 
substrate/stiff coating $\alpha=1$, compliant coating/stiff substrate, stiff coating/complaint substrate. In the case of an aluminum substrate coated with $\mathrm{U}, \alpha \sim 3$, which we will consider as compliant coating to a compliant substrate. Extensive work performed by BR shows that for the case, $\alpha=3$, the number of terms in Röll's equation would have been sufficient, as long as the thickness ratio is less than $30 \%$; if the coating thickness ratio becomes larger than $30 \%$, Roll's equation would start to deviate significantly from BR equation and would underestimate the overall residual stress.

$$
\begin{aligned}
& \sigma_{\text {Stoney }}=\frac{-E_{s} \cdot t_{s}^{2}}{6 \cdot t_{c} \cdot\left(1-v_{s}\right) \cdot R} \\
& \sigma_{R o ̈ l l}=\frac{-E_{s} \cdot t_{s}^{2}}{6 \cdot t_{c} \cdot\left(1-v_{s}\right) \cdot R} \cdot[1+\beta(4 \gamma-1)] \\
& \sigma_{B R}=\frac{-E_{s} \cdot t_{s}^{2}}{6 \cdot t_{c} \cdot\left(1-v_{s}\right) \cdot R} \cdot\left[1+\beta(4 \gamma-1)+\beta^{2} \cdot\left[\gamma^{2} \cdot(\beta-1)+4 \gamma+\frac{(1-\gamma)^{2}}{1+\beta}\right]\right]
\end{aligned}
$$

where:

$$
\begin{aligned}
& \gamma=\frac{E_{c}\left(1-v_{s}\right)}{E_{s}\left(1-v_{c}\right)} \\
& \beta=\frac{t_{c}}{t_{s}} \\
& R=\frac{L^{2}}{8 \cdot \delta_{\max }}
\end{aligned}
$$

where $\mathrm{R}$ is the radius of curvature, $\mathrm{L}$ is the length of the coating $(20 \mathrm{~mm})$, and $\delta \mathrm{max}$ is the maximal deflection. Additionally, c denotes coating and s denotes substrate. As can be seen, the BR equation has additional higher order terms to account for the coating thickness and properties. The stresses were calculated using all three equations 
and for a thin film of 1 micron all three equations gave the same result. However, since we are interested in films $\sim 25 \mu \mathrm{m}$ thick, we have selected to use only the BR equation, since it was derived to work for thin and thick coatings. All stress values presented throughout this paper have been calculated using BR equation.

\subsection{Residual Stress Results}

Figure 3 shows the residual stress values of the Uranium coatings as a function of film thickness. At our target thickness of $25 \mu \mathrm{m}$, a residual stress of $-1 \mathrm{GPa}$ was calculated which is noticeably less than the $-3.5 \mathrm{GPa}$ residual stress calculated for the $1 \mu \mathrm{m}$ thick film. No attempts were made to make thicker coatings since our $U$ source has a constant coating rate for the first 4 hours but seems to degrade after longer periods, so this allows us to predict the coating thickness. Note that as the coating thickness increases, the stress becomes less compressive. However, at $25 \mu \mathrm{m}$ film thickness, the residual stress is close to $-1.0 \mathrm{GPa}$, which is very high; therefore, changes in the coating parameters (the addition of a negative bias voltage) had to be introduced in an attempt to lower the residual stresses.

Figure 4 shows a reduction of residual stresses by introducing a bias voltage. We were able to reduce the stresses by over half by applying a bias voltage. The most significant reduction in stress occurred at $-200 \mathrm{~V}$. The $-300 \mathrm{~V}$ coating run had a more modest decrease than at $-200 \mathrm{~V}$ and it also show a large deviation in stress distribution for scans A, B, C and D.

In this particular study we encountered two major unknown factors that played a significant role when trying to anticipate our coating behavior: the complex crystal 
structure of $U$, and the coatings thickness. Literature on thick films $(.25 \mu \mathrm{m})$ is very sparse with few exceptions $[8,19]$. Current research on sputtered films deposited with a bias voltage is based on mostly on thin films $(<300 \mathrm{~nm})$ with FCC and BCC structures. Patten et. al study the effects of a small substrate bias (-70V) on the microstructure of thick $\mathrm{Cu}$ and $\mathrm{Cr}$ films (up to $1.0 \mathrm{~mm}$ ) $[19,20]$, however there is no measure of residual stresses. For thin films, there are a few samples of the effects of bias on the residual stresses. Cheng et al. [9] deposited $250 \mathrm{~nm}$ of $\mathrm{Cu}$ on (100) silicon wafers and applied a negative bias voltage from -50 to $-600 \mathrm{~V}$. They observed that, as the bias voltage increased, the residual stresses went form $200 \mathrm{MPa}$ at $0 \mathrm{~V}$ to $-300 \mathrm{MPa}$ at $600 \mathrm{~V}$, so their coating became compressive as the bias voltage was increased. Cr coatings of $150 \mathrm{~nm}$ thickness show a similar behavior to the $\mathrm{Cu}$; as bias increased to $-500 \mathrm{~V}$, the residual stress became compressive to $-2.2 \mathrm{GPa}$ [11]. Effects of the bias on the film roughness were small and did not present a trend, as has been shown by other researchers $[9,21]$. The effect of the bias on thin films is due to the increase of energetic particles, which causes an "atom peening mechanism" and explains the transition from tensile to compressive $[11,14]$. It would be difficult to speculate why the Uranium films becomes less compressive as the bias is increased; it is known that denser and thicker films are more often compressive. But with Uranium, we have a multitude of problems. First, depending on texture, the coefficient of thermal expansion in $U$ can be drastically different [22], thus changing the contribution of the extrinsic stresses on the total stress value. Another unknown is the in-situ stress as the coating is formed; as the plasma temperature increases, there is an influx of atoms that can form $\alpha, \beta$, or $\gamma$ Uranium, which would affect the intrinsic stresses of the coating. Once the PVD process is completed, the 
film is $\alpha \mathrm{U}$ but, if the coating is initially a different phase, the transition from one phase to $\alpha \mathrm{U}$ can produce additional stress to the coating.

We proposed that an in-situ test to read the stress as the coating is added would give an inside look at the intrinsic stresses formed during the deposition. Additionally, further investigations of the $\mathrm{U}$ phase transition during PVD would allow a very complete assessment on the formation of residual stresses.

\section{Conclusions}

We have successfully produced thick Uranium coatings $(25 \mu \mathrm{m})$ on an $\mathrm{Al}$ substrate. The coatings adhere well to the substrate and are characterized as fully dense with homogeneous thickness throughout the length of the coating. The film deflection was measured by profilometry and the stresses calculated using the Benabdi/Roche equation. The residual stresses were presented as a function of thickness and applied negative bias voltage. The stresses measured were always compressive; however, increasing the coating thickness and adding a bias voltage presented a trend towards more tensile stresses and thus an overall reduction of residual stresses.

\section{Acknowledgements}

This work was performed under the auspices of the U.S. Department of Energy by the University of California, Lawrence Livermore National Laboratory under Contract No. W-7405-Eng-48. The authors thank L. carpenter, J. Lotscher, R. del Chiaro and E. Sedillo at LLNL for sample preparation and characterization, and Mr. P. O'Hara at Ambios Technology, Inc. for helpful discussions. 


\section{References}

1. W.D. Wilkinson, Uranium Metallurgy. Vol. I. 1962, New York: Interscience Publishers.

2. J.V. Cathcart, Gaseous Oxidation of Uranium Alloys, in Physical Metallurgy of Uranium Alloys, J.J. Burke, et al., Editors. 1976, Brook Hill Publishing Company: Massachusetts. p. 775.

3. T. Gouder and C.A. Colmenares. Surface Science, 1993. 295: p. 241.

4. T. Gouder and C.A. Colmenares. Journal of Alloys and Compounds, 1994. 213/214: p. 500.

5. X. Xiaobin, L. Kezhao, L. Xuechao, and Z. Yongbin. Rare Metal Materials and Engineering, 2003. 32(1): p. 67.

6. L.B. Freund and S. Suresh, Thin Film Materials: Stress, Defect Formation and Surface Evolution. 2003, Cambridge: Cambridge University Press.

7. W.D. Nix. Metallurgical Transactions, 1989. 20A: p. 2217.

8. J.A. Thornton. Journal of Vacuum Science and Technology, 1974. 11(4): p. 666.

9. Y.H. Cheng, B.K. Tay, S.P. Lau, X. Shi, and H.S. Tan. Journal of Vacuum Science and Technology A, 2001. 19(5): p. 2102.

10. M. Oden, J. Almer, and G. Hakansson. Surface Coatings Technology, 1999. 121121: p. 272.

11. A. Misra and M. Nastasi. Applied Physics Letters, 1999. 75(20): p. 3123.

12. J. Gunnars and U. Wiklund. Materials Science and Engineering, 2002. 336A: p. 7.

13. Z.B. Zhao, J. Hershberger, S.M. Yalisove, and J.C. Bilello. Thin Solid Films, 2002. 415: p. 21.

14. J.A. Thornton and D.W. Hoffman. Thin Solid Films, 1989. 171: p. 5.

15. M. Benabdi and A.A. Roche. Journal of Adhesion Science and Technology, 1997. 11(2): p. 281.

16. K. Roll. Journal of Applied Physics, 1976. 47(7): p. 3224.

17. G.G. Stoney. Proceedings of the Royal Society of London, 1909. 82A: p. 172.

18. S. Timoshenko. Journal of the Optical Society of America, 1925. 11: p. 233.

19. J.W. Patten, E.D. McClanahan, and J.W. Johnston. Journal of Applied Physics, 1971. 42(11): p. 4371.

20. J.W. Patten and E.D. McClanahan. Journal of Applied Physics, 1972. 43(11): p. 4811.

21. C. Gautier, G. Moulard, J.P. Chatelon, and G. Motyl. Thin Solid Films, 2001. 384: p. 102.

22. $\quad$ L.T. Lloyd and C.S. Barrett. Journal of Nuclear Materials, 1966. 18: p. 55. 
To be submitted to Journal of Nuclear Materials - not for circulation

\section{Figures}
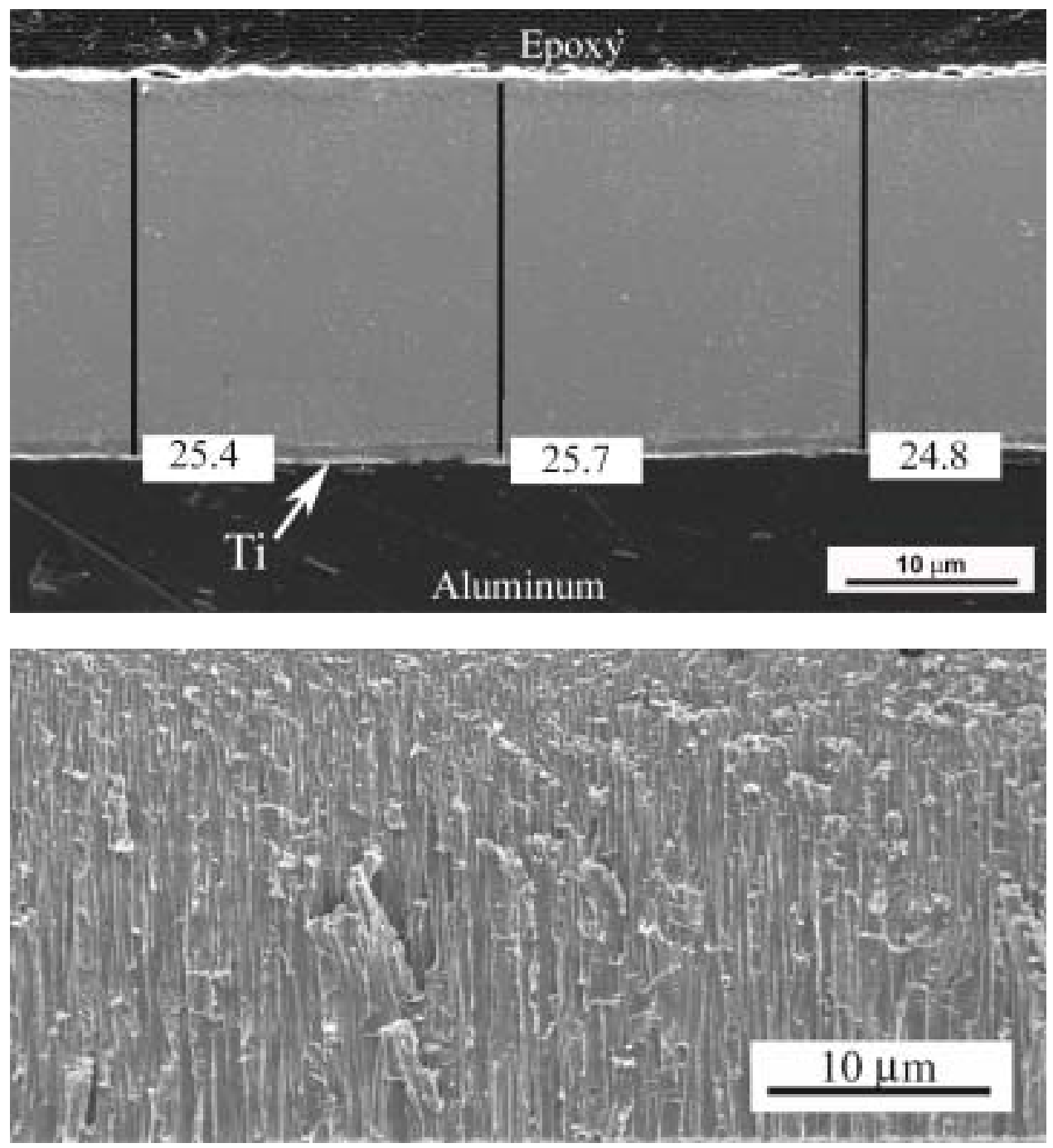

Figure 1. SEM micrographs of a) polished coated surface noting uniform coating thickness $b$ ) coating fracture surface 

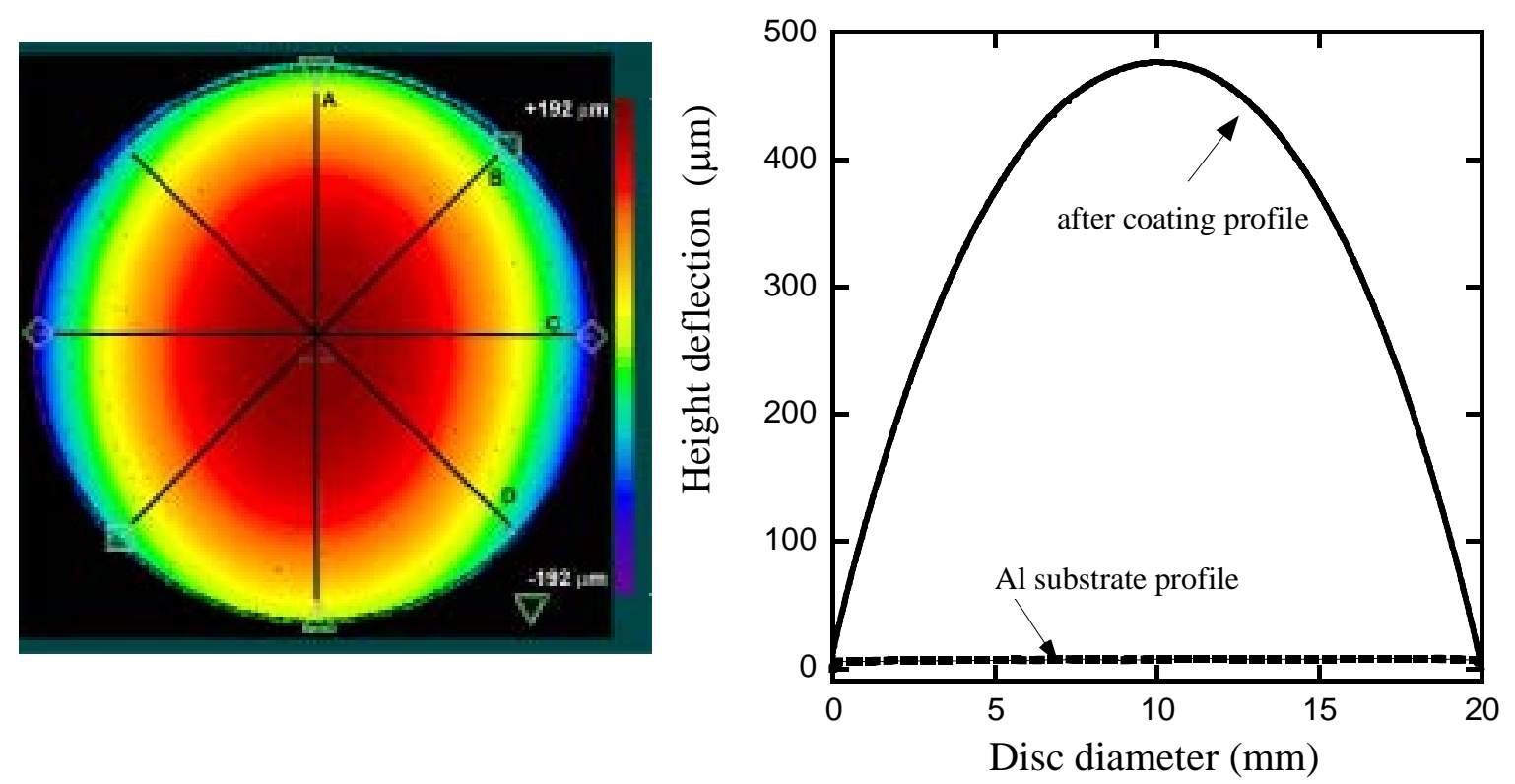

Figure 2. White light profilometry from sample 5 coated using $-300 \mathrm{~V}$ bias a) scan lines A, B, C, D and b) Deflection profile before and after coating for scan line C 
To be submitted to Journal of Nuclear Materials - not for circulation

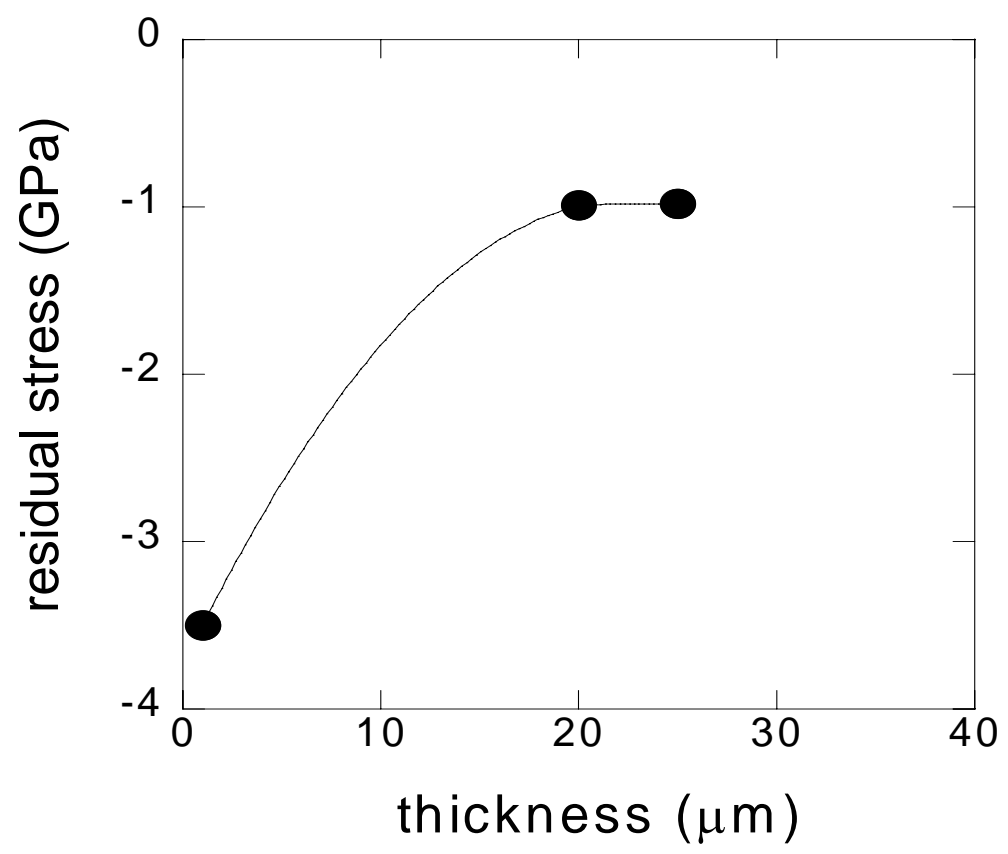

Figure 3. Calculated residual stresses using BR equation as a function of coating thickness (PVD without bias) 
To be submitted to Journal of Nuclear Materials - not for circulation

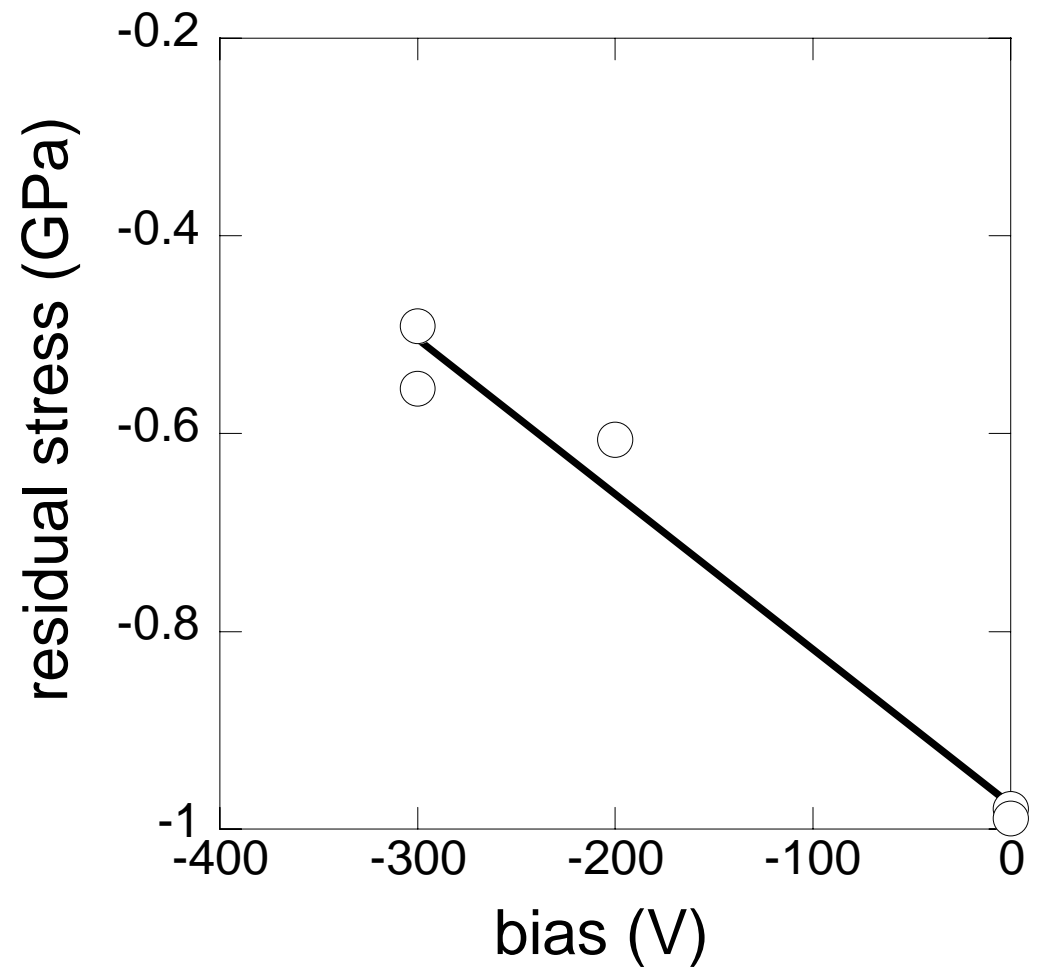

Figure 4.Residual stress as a function of bias voltages at coating thickness of $\sim 25 \mu \mathrm{m}$ 